\title{
Computed Tomographic Findings of Malignant Bowel Neoplasms: A Retrospective Study
}

\section{ABSTRACT}

Introduction: Malignant neoplasms of bowel particularly colorectal carcinomas are third commonest cause of death all over world. Computed Tomography (CT) plays a very important role in evaluation of malignant bowel neoplasms. CT examination for gastrointestinal tract evaluates the intestinal lumen along with demonstration of intestinal wall, adjacent tissues and solid viscera.

Aim: To evaluate malignant neoplasms of small and large intestine and also to define the various CT findings in malignant bowel neoplasms, extra-intestinal involvement to stage intestinal neoplasms and to accurately characterise the tumour histologically as far as possible.

Materials and Methods: A retrospective descriptive study included 38 patients who were proven to have malignancy of bowel on biopsy, underwent CT abdomen in major public hospital in a period of from November 2014 to May 2017 and evaluated for various CT findings in malignant bowel neoplasms in terms of involved intestine, length of diseased intestinal segment, degree of intestinal wall thickening, extra-intestinal involvement to stage bowel neoplasms and to accurately characterise the tumour histologically as far as possible. Data were tabulated and presented as frequency ( $\mathrm{n}$ ) and precentage (\%).
Results: In small intestine, ileum is the commonest site of involvement seen in 5 cases (13\%), whereas rectum 10 cases $(26.3 \%)$ was the commonest site of involvement in large intestine. Short segment involvement of bowel is more common 27 cases $(71.1 \%)$ than long segment involvement 11 cases (28.9\%). Circumferential wall thickening is more common in 33 cases $(86.8 \%)$ than eccentric wall thickening 5 cases (13.2\%). Lymph nodal involvement was seen in 17 cases (44\%) and metastasis to liver was also seen in 11 cases $(28.9 \%)$. Local invasion with involvement of surrounding structures was seen in 4 cases (10.5\%). Adenocarcinoma was the commonest histological subtype seen in the highest number of 23 cases $(60.5 \%)$, followed by lymphoma in 9 cases (23.6\%), mucinous adenocarcinoma in 4 cases (10.5\%) and few cases of about 2 cases (5.2\%) were Gastrointestinal Stromal Tumour (GIST).

Conclusion: Computed Tomography (CT) imaging findings like involved intestine, length of diseased intestinal segment, degree of intestinal wall thickening, extra intestinal involvement with respect to involvement of surrounding structures, lymph nodal involvement, distant metastasis along with histological type in most cases could be found, thus permitting tumour characterisation which can provide very useful guide in diagnosis of malignant neoplasms of small and large intestine.

Keywords: Computed tomography, Large intestine, Metastasis, Small intestine, Wall thickening

\section{INTRODUCTION}

Abdominal studies were originally confined to solid organs in retro peritoneum extending eventually into peritoneal cavity [1]. Bowel details were not referred owing to slow data acquisition and lack of definition. Major improvement in computing science as well as development of spiral technique has now led to large volume data acquisition [2-4]. Thus, in recent times CT has been shown to be an essential tool in radiologic evaluation of gastrointestinal tracts [5]. Barium study and endoscopy remain the method of choice in initial detection of most of alimentary tract disease. However, both techniques are limited to examination of mucosal surface, caliber and contour of bowel segment. They provide little and indirect information regarding intramural or extrinsic abnormalities. CT examination for gastrointestinal tract not only evaluates the bowel lumen, but its major contribution consists of demonstrating bowel wall and the adjacent tissues and organs $[6,7]$. Malignant neoplasms of bowel particularly colorectal carcinomas are third commonest cause of death all over world. CT plays a very important role in evaluation of malignant bowel neoplasms [8].

The objectives of the study were to evaluate the various CT findings in malignant bowel neoplasms, extra-intestinal involvement to stage bowel neoplasms and to accurately characterise the tumour histologically as far as possible.

\section{MATERIALS AND METHODS}

A retrospective descriptive study was carried out in the Department of Radiology, Maharajah's Institute of Medical Sciences (MIMS), Nellimarla, Vizianagaram district.
Inclusion criteria: This study included a total of 38 patients of proven bowel malignancy on biopsy who underwent CT examination of the abdomen from November 2014 to May 2017. All those patients who presented with history of melena, constipation, diarrhoea, alternate diarrhoea and constipation, weight loss and anorexia were included in the study.

Exclusion criteria: Patients with synchronous or metachronous malignancy of other organs in addition to bowel malignancy, severely decompensated patients, pregnancy and patients with deranged kidney function test.

Formal sample size calculation was not done. All the data of patients fullfilling the inclusion and exclusion criteria along with informed consent, were enrolled in the study.

\section{Procedure}

The patient was placed supine on the Computed Tomography table. The head was immobilised with head rest. Hands were folded above the shoulder around the head. A scout topogram was obtained from domes of diaphragm down to the symphysis pubis. Appropriate positioning with help of laser mark with respect to the field of interest was done. Scan parameters included 220 mAs (milliampere-second)/140 (kVp) Kilo voltage peak. Precontrast contiguous sequential scans with slice thickness of $10 \mathrm{~mm}$ were taken from domes of diaphragm down to the level of pubic symphysis followed by oral and post-intravenous contrast scans were done for adequate bowel distension and luminal enhancement. History and physical examination of all patients was systematically carried out. 
All the patients were required to be fasting for at least six hours prior to the examination.

\section{Contrast}

Oral contrast: Patients were made to drink $300-400 \mathrm{~mL}$ of solution prepared with two ampules of $60 \%$ iodinated contrast mixed in $11 / 2 \mathrm{~L}$ of plain water at 20-30 minutes intervals with 100-200 mL of same solution to be given on CT table for adequate distension of stomach.

Rectal contrast: To opacify the rectum and distal colon, $200-500 \mathrm{~mL}$ of rectal contrast is given rectally as a standard procedure. In female married patients, vaginal tampon is inserted in the vagina to delineate anatomic structures in pelvis.

Post-intravenous contrast: A bolus of $100 \mathrm{~mL}$ of $76 \%$ iodinated contrast was injected at 1.7 to $2 \mathrm{~mL} / \mathrm{sec}$ via a pressure injector. Scan delay is $46-50$ seconds, collimation $5 \mathrm{~mm}$, table feed $5 \mathrm{~mm}$, reconstruction interval $5 \mathrm{~mm}$, phases of acquisition single phase, dual phase, if needed, region scanned from above domes of diaphragm down to the symphysis pubis. Delayed scans were obtained whenever it was deemed necessary. Multiplanar reconstruction and Three Dimensional (3D) volume rendering techniques can be used to better visualise colon anatomy and the location of the suspected mass or abnormality. Repeated imaging can be done with the patient in prone position, if appropriate or with more air or contrast material after administration to distend collapsed bowel parts. A scan time of 20 minutes was observed for each case.

Normal small bowel wall is thin, measuring between 1 and $2 \mathrm{~mm}$ when the lumen is well-distended. However, depending on the degree of luminal distention, the thickness of the usual small bowel wall varies slightly. As a consequence, multiple standards for the diagnosis of small bowel wall thickening have been used. The wall is also not seen when the lumen of the small bowel is distended. If the bowel is incompletely collapsed, the wall measures between $2 \mathrm{~mm}$ and $3 \mathrm{~mm}$ and is of symmetric thickness. In these cases, it is essential to relate the degree of thickness of similarly distended segments to exclude disorders [9]. The usual thickness of the colonic wall differs greatly depending on the degree of distention. When the colon is distended, the wall should measure less than $3 \mathrm{~mm}$, and it is often imperceptible [9]. The actual thickness is often difficult to assess due to fecal matter, fluid, or colonic redundancy. The true thickness will often be revealed prudently by following the colonic wall to a region where the colon is well-distended with gas. Luminal margins are usually smooth being well-outlined by the contrast/air. The outer colonic margin is sharply outlined by surrounding homogenous pericolic fat [9].

After an appropriate bolus of IV contrast material, the regular intestinal wall strengthens. In patients, who have been given water as an oral contrast agent, the enhancement is also more readily detected. In these situations, next to the low attenuation fluid in the lumen, the strengthened bowel wall is well-depicted. On the mucosal part of the bowel wall, enhancement is usually greater. Identifying that the wall is not thickened and that there is no perienteric inflammation, will allow one to distinguish normal improvement from the disease process [9]. Fat in mesentery has the same attenuation as fat elsewhere in the body. Major arteries and veins are identified as branching structures within mesenteric fat and do exceed $3 \mathrm{~mm}$ in diameter. Mesenteric lymph nodes are occasionally observed in mesenteric fat and do not exceed $3 \mathrm{~mm}$. No soft tissue structure in mesentery exceeds $4 \mathrm{~mm}$ in normal individual.

CT interpretative criteria for malignant bowel neoplasms which were used in the current study were [9]:

- $\quad$ Site involved (small bowel-jejunum and ileum, large bowelcaecum, colon, rectum and anal canal)

- Length of bowel involved (short segment: less than $10 \mathrm{~cm}$, long segment: more than $10 \mathrm{~cm}$ )

- $\quad$ Degree of bowel wall thickening (more than $2 \mathrm{~cm}$ and less than $2 \mathrm{~cm})$

- $\quad$ Circumferential/eccentric bowel wall thickening
- Attenuation and enhancement pattern of involved bowel wall (Homogenous attenuation and heterogenous attenuation).

- Extra-intestinal involvement includes perienteric/surrounding involvement, lymphadenopathy, and solid organ abnormalities/ metastasis.

\section{STATISTICAL ANALYSIS}

Statistical data was presented in the form of frequency and percentages for malignant lesions of small and large intestine.

\section{RESULTS}

The present study included 38 patients of biopsy proven malignant bowel neoplasm with age between 3 and 70 years. Age groups between 40-59 years formed the bulk of cases (47.36\%). Male cases $(68.5 \%)$ were more than female cases (31.5\%) as shown in [Table/Fig-1].

\begin{tabular}{|l|c|c|}
\hline Variables & No. of patients & Percentage \\
\hline Age group (years) & 3 & $7.9 \%$ \\
\hline $0-9$ & 1 & $2.6 \%$ \\
\hline $10-19$ & 5 & $13.1 \%$ \\
\hline $20-29$ & 7 & $18.5 \%$ \\
\hline $30-39$ & 9 & $23.68 \%$ \\
\hline $40-49$ & 9 & $23.68 \%$ \\
\hline $50-59$ & 4 & $10.5 \%$ \\
\hline $60-69$ & \multicolumn{2}{|l|}{} \\
\hline Sex & 26 & $68.42 \%$ \\
\hline Male & 12 & $31.57 \%$ \\
\hline Female & \multicolumn{2}{|l|}{} \\
\hline TTable/Fig-1]: Age and Sex-wise distribution of cases ( $\mathrm{n}=38)$. \\
\hline
\end{tabular}

In small bowel, ileum was the commonest site of involvement (13.15\%), whereas rectum (26.3\%) was commonest site of involvement in the large bowel [Table/Fig-2]. Based on the length of bowel segment involved, cases with short segment involvement of bowel was more common $27(71.1 \%)$ than long segment involvement 11 (28.9\%). Circumferential bowel wall thickening is more common (86.8\%) than eccentric wall thickening (13.2\%) [Table/Fig-3]. Lymph nodal involvement was seen in $44 \%$ cases and metastasis to liver was also seen in $28.9 \%$ cases [Table/ Fig-4]. Based on the enhancement pattern of cases, homogenous

\begin{tabular}{|l|c|c|}
\hline Site involved & Number of patients & Percentage \\
\hline Jejunum & 1 & $2.6 \%$ \\
\hline Ileum & 5 & $13.5 \%$ \\
\hline Ileocaecal & 3 & $7.8 \%$ \\
\hline Caecum & 1 & $2.6 \%$ \\
\hline Ascending colon+caecum & 2 & $5.3 \%$ \\
\hline Ascending colon & 4 & $10.5 \%$ \\
\hline Transverse colon & 5 & $13.3 \%$ \\
\hline Descending colon+sigmoid colon & 1 & $2.6 \%$ \\
\hline Sigmoid colon+Rectum & 3 & $7.8 \%$ \\
\hline Rectum & 10 & $26.3 \%$ \\
\hline Rectum +anal canal & 3 & $7.8 \%$ \\
\hline [Table/Fig-2]: Site of GIT involved in the malignant neoplasm. & \\
\hline
\end{tabular}

\begin{tabular}{|c|c|c|c|c|}
\hline \multirow{2}{*}{$\begin{array}{l}\text { Preventive } \\
\text { studies }\end{array}$} & \multicolumn{2}{|c|}{$\begin{array}{l}\text { Circumferential wall } \\
\text { thickening }\end{array}$} & \multirow{2}{*}{$\begin{array}{c}\text { Mass lesion/eccentric } \\
\text { lesion }\end{array}$} & \multirow{2}{*}{$\begin{array}{l}\text { Total number } \\
\text { of patients }\end{array}$} \\
\hline & $<2 \mathrm{~cm}$ & $>2 \mathrm{~cm}$ & & \\
\hline $\begin{array}{l}\text { Number of } \\
\text { patients }\end{array}$ & 5 & 28 & 5 & 38 \\
\hline Percentage & $13.2 \%$ & $73.6 \%$ & $13.2 \%$ & $100 \%$ \\
\hline
\end{tabular}


enhancement pattern was seen in 11 (28.9\%) number of cases whereas heterogenous enhancement pattern was seen in 27 (71.1\%) cases. Adenocarcinoma was the commonest histological subtype seen in highest number of patients 23 (60.6\%) followed by lymphoma in $23.6 \%$ of cases, mucinous adenocarcinoma in $10.5 \%$ cases and few cases of about 2 (5.2\%) were GIST [Table/Fig-4]. From the [Table/Fig-5-8] study key findings were reported based on CT characteristics with each histopathologically proven neoplasm.

\begin{tabular}{|c|c|c|}
\hline Distribution of cases & Number of patients & Percentage (\%) \\
\hline \multicolumn{3}{|l|}{ Extraintestinal involvement } \\
\hline Local invasion & 4 & $10.5 \%$ \\
\hline Lymph node involvement & 17 & $44.7 \%$ \\
\hline Liver metastasis & 11 & $28.9 \%$ \\
\hline \multicolumn{3}{|l|}{ Histological type } \\
\hline Adenocarcinoma & 23 & $60.5 \%$ \\
\hline Lymphoma & 9 & $23.7 \%$ \\
\hline Mucinous adenocarcinoma & 4 & $10.5 \%$ \\
\hline GIST & 2 & $5.2 \%$ \\
\hline
\end{tabular}

\section{DISCUSSION}

In diagnosing malignant neoplasms of the small and large intestine, numerous studies have shown the accuracy of the CT than traditional clinical-radiographic evaluation methods. In our study of 38 patients of the biopsy proven malignant bowel neoplasm, we evaluated the role of CT imaging in characterising the CT features in malignant bowel neoplasm based on involved intestine, length of the diseased intestinal segment, degree of intestinal wall thickening, extra-intestinal involvement, lymph nodal involvement and solid organ metastasis, etc. The commonly affected age groups were of 40-59 years (47.2\%) and males (68.5\%) were more affected than females. These findings were in line with the study conducted by Ravi Kumar $Y$ et al., which mentioned most affected age groups as 51 to 60 years $(23.1 \%)$ and majority of the cases were males (63.5\%) [10].

Adenocarcinoma is the commonest malignant neoplasm of the colon. The small intestine is uncommon site for adenocarcinoma. Out of 38 patients, 23 were proven to have adenocarcinoma. The rectum was the commonest site of involvement seen in 13 patients (26.3\%), and descending colon was affected less and seen only in one case (2.6\%). Twenty out of 23 patients (84\%) showed short segment involvement i.e., less than $10 \mathrm{~cm}$. Remaining three

\begin{tabular}{|c|c|c|c|c|c|c|c|c|}
\hline \multirow{4}{*}{$\begin{array}{l}\text { Histopath diagnosis } \\
\text { Adenocarcinoma }(n=23)\end{array}$} & \multicolumn{2}{|c|}{ Length of bowel involved } & \multicolumn{2}{|c|}{$\begin{array}{l}\text { Degree of bowel } \\
\text { wall thickening }\end{array}$} & \multicolumn{2}{|c|}{$\begin{array}{l}\text { Attenuation and enhancement } \\
\text { pattern of involved bowel wall }\end{array}$} & \multirow{2}{*}{\multicolumn{2}{|c|}{$\begin{array}{l}\text { Extraintestinal involvement includes } \\
\text { perienteric/surrounding involvement, } \\
\text { lymphadenopathy, and solid organ } \\
\text { abnormalities/metastasis }\end{array}$}} \\
\hline & Short segment & Long segment & $>2 \mathrm{~cm}$ & $<2 \mathrm{~cm}$ & Homogenous & Heterogenous & & \\
\hline & \multirow{2}{*}{20} & \multirow{2}{*}{3} & \multirow{2}{*}{17} & \multirow{2}{*}{6} & \multirow{2}{*}{8} & \multirow{2}{*}{15} & Lymphadenopathy & 11 \\
\hline & & & & & & & Liver metastasis & 2 \\
\hline \multirow{3}{*}{ Lymphoma (n=9) } & \multirow{3}{*}{6} & \multirow{3}{*}{3} & \multirow{3}{*}{9} & \multirow{3}{*}{0} & \multirow{3}{*}{3} & \multirow{3}{*}{6} & $\begin{array}{l}\text { Abdominal } \\
\text { lymphadenopathy }\end{array}$ & 4 \\
\hline & & & & & & & Splenic deposits & 1 \\
\hline & & & & & & & Liver deposits & 2 \\
\hline \multirow{2}{*}{$\begin{array}{l}\text { Mucinous } \\
\text { adenocarcinoma }(n=4)\end{array}$} & \multirow{2}{*}{4} & \multirow{2}{*}{0} & \multirow{2}{*}{4} & \multirow{2}{*}{0} & \multirow{2}{*}{0} & \multirow{2}{*}{4} & Lymphadenopathy & 2 \\
\hline & & & & & & & Ascites liver scalloping & 1 \\
\hline GIST (n=2) & 2 & 0 & 2 & 0 & 0 & 2 & - & \\
\hline
\end{tabular}

[Table/Fig-5]: Computed Tomography (CT) characteristics with each histopath proven neoplasm.

Histopath: Histopathological
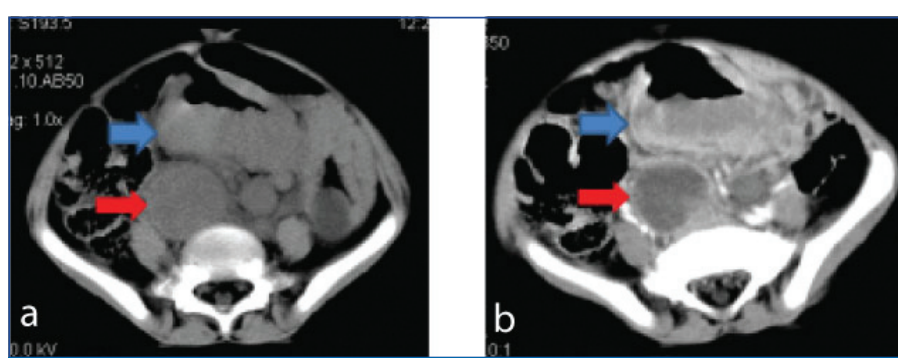

[Table/Fig-6]: Rectosigmoid adenocarcinoma with pelvic lymphadenopathy: a) NECT (at the level of pelvis) showing eccentric bowel wall thickening of $3.5 \mathrm{~cm}$ in rectosigmoid region (blue arrow) with pelvic lymphadenopathy (red arrow); b) IV Contrast enhanced CT showing heterogenous enhancement of rectosigmoid wall thickening (blue arrow) with rim enhancing pelvic lymphadenopathy (red arrow). NECT: Non-enhance computed tomography; CT: Computed tomography
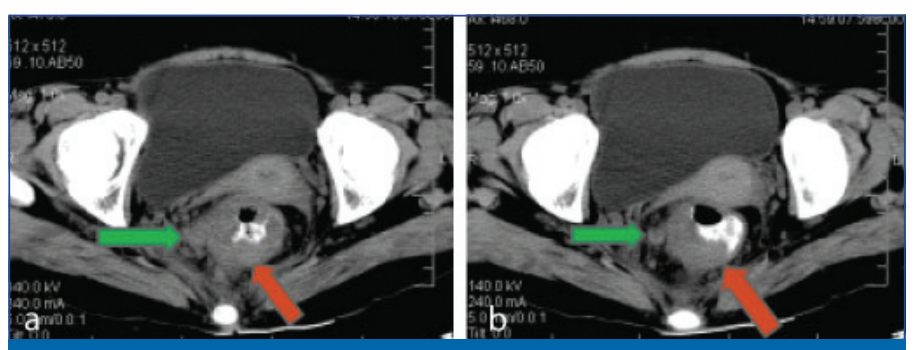

[Table/Fig-7]: Rectal adenocarcinoma with perirectal lymphadenopathy: a) and b) CT with rectal contrast (at the level of lower pelvis) showing eccentric rectal wall thickening of 2 to $2.5 \mathrm{~cm}$ (red arrows) with perirectal lymphadenopathy (green arrows. CT: Computed tomography
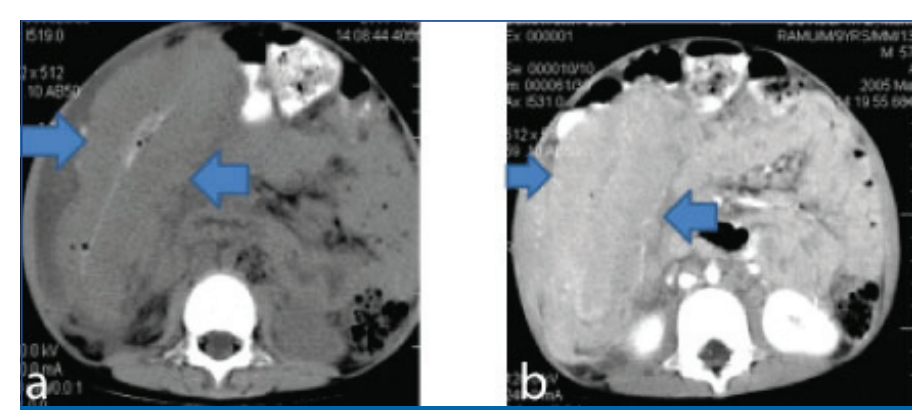

[Table/Fig-8]: Colonic lymphoma: a) CT with oral contrast (at the level of upper abdomen) showing long symmetric concentric wall thickening (blue arrows) of 2 to $3 \mathrm{~cm}$ involving the hepatic flexure and transverse colon. b) IV Contrast enhanced CT showing mild heterogenous enhancement of wall thickening (blue arrows).

IV: Intravenous

patients showed long segment involvement i.e., more than $10 \mathrm{~cm}$. Short segment involvement was commonly seen in malignant lesion than long segment which was seen in inflammatory conditions and these finding were in accordance to the Macari $M$ and Balthazar EJ [9]. Average diseased bowel wall thickness seen in 17 out of 23 patients was more than $2 \mathrm{~cm}$. This finding was consistent with the study by Macari $\mathrm{M}$ and Balthazar EJ, which stated that wall thickening greater than $2 \mathrm{~cm}$ is usually present in neoplastic conditions, whereas benign conditions result in bowel wall thickening of less than $2 \mathrm{~cm}$ [9]. In the present study, six patients even though diseased bowel wall thickness was less than $2 \mathrm{~cm}$, they were proven 
to be malignant. Fifteen out of 23 patients showed heterogeneous mixed patterns of enhancement on postcontrast series whereas 8 patients showed homogenous enhancement patterns. These two patterns of enhancement are usually seen in malignant lesion. In these conditions, other factors like degree of bowel wall thickening, circumferential/eccentric bowel wall thickening, length of the involved segment, and associated extra intestinal abnormalities are important in establishing the correct diagnosis. In cases of neoplasm, homogeneous attenuation correlates with size of the tumour. These findings are consistent with various studies $[9,11,12,13]$. Six out of 13 patients of rectal adenocarcinoma showed perirectal and presacral lymph nodal involvement. Any lymph node in presacral and perirectal region is considered malignant irrespective of the size, since inflammatory nodes are never seen in these regions. Other lymph nodes that were involved were mesenteric, portal, aortic, aortocaval, iliac and inguinal group. All these nodes were more than $1 \mathrm{~cm}$ in short axis diameter however, whether they were malignant or not, could not be accurately mentioned based on CT features. Eight out of 23 patients of adenocarcinoma showed liver metastasis. This finding was similar as study done by Horton KM et al., [11]. CT has an established role in the detection of hepatic metastases in patients with colorectal cancer.

Nine out of 38 patients were proven to be lymphoma on the biopsy, of which majority (4 out of 9) patients showed involvement of the ileum. Most characteristic finding seen in six out of nine patients of lymphoma was the short segment circumferential involvement with aneurysmal dilatation of the bowel. This dilatation was secondary to loss of muscle tone of the intestinal wall caused by extensive invasion of muscle layer and neural plexus. These findings are consistent with the study of Balthazar EJ et al., [14]. Six out of nine patients of lymphoma showed heterogenous mixed enhancement pattern and three patients showed homogenous pattern. Four out of nine patients of lymphoma showed enlarged abdominal lymph nodes, two patients showed liver deposits and one patient had splenic deposit.

Four out of 38 patients (10.5\%) were proven to be mucinous adenocarcinoma of the large bowel and two out of four patients showed foci of calcifications within mass, two patients showed lymph nodal enlargement one of which showed calcification. One patient showed ascites with scalloping of liver surface. Heterogenous mixed pattern of enhancement was seen in all four patients. Presence of tumoural calcification and calcified lymph nodes along with heterogenicity on postcontrast is common finding in mucinous adenocarcinoma. These findings correlated with the findings by Hussain SM et al., [15]. All the four patients showed short segment involvement.

Two out of 38 patients (5.2\%) were proven to be GISTs, one involving the jejunum and another involving the transverse colon. Both these show varying degree of internal necrosis or cystic changes. Pattern of growth in jejunal GIST was of endoenteric type and that involving the transverse colon was of exocolic type with large exophytic component showing cystic changes.

\section{Limitation(s)}

Small sample size, single slice CT machine are the limitations of this study.

\section{CONCLUSION(S)}

Computed tomography imaging findings like involved intestine, length of diseased intestinal segment, degree of intestinal wall thickening, extra intestinal involvement with respect to involvement of surrounding structures, lymph nodal involvement, distant metastasis along with histological type in most cases could be found. Thus, permitting tumour characterisation which can provide very useful guide in diagnosis of malignant neoplasms of small and large intestine. The role of CT in diagnosing and altering the treatment plans for a wide range of causes of small and large intestine neoplasms was assertively determined in this study.

\section{REFERENCES}

[1] Freeman AH. CT and bowel diseases. BJR. 2001;74(877):04-14

[2] Evers BM. Sabiston textbook of surgery. 18 $8^{\text {th }}$ edition. Noida: Elsevier. 2009; 1289

[3] Frager D. Intestinal obstruction role of CT. Gastro enteral Clin North Am. 2002;31:777-99.

[4] Sarr MG, Bulkley GB, Zuidema GD. Preoperative recognition of intestinal strangulation obstruction: prospective evaluation of diagnostic capability. Am J Surg. 1983;145(1):176-82

[5] Lorgan JG, DuBrowRA. The computed tomographic appearances and clinical significance of intussusception in adults with malignant neoplasms. $\mathrm{Br} \mathrm{J}$ Radiol. 1990;63:257-63

[6] Megibow AJ, Balthazar EJ, Cho KC, Medwid SW, Birnbaum BA, Noz ME. Bowel obstruction: Evaluation with CT. Radiology. 1991;180(2):313-18.

[7] Kim HK, Cho MJ, Ha S, Seo MJ, Moon SG, Oh JH. Adenocarcinoma of the proximal jejunum misdiagnosed as gastroparesis. The Korean Journal of Helicobacter and Upper Gastrointestinal Research. 2019;19(3):202-06.

[8] Jahromi AH, Kim RH, Chu QD, LiBD. Small Bowel Cancer (excluding gastrointestinal stromal tumours and carcinoid): Clinical management. The American Cancer Society's Oncology in Practice. Wiley publications. USA. 2018; 69-81.

[9] Macari M, Balthazar EJ. CT of bowel wall thickening: Significance and pitfalls of interpretation. AJR Am J Roentgenol. 2001;176:1105-16.

[10] Yeli RK, Patil SV, Nagababu P. Multidetector computed tomography in small and large bowel lesions. International Journal of Contemporary Medicine Surgery and Radiology. 2018;3(1):151-54.

[11] Horton KM, Juluru K, Montogomery E, Fishman EK. Computed tomography imaging of gastrointestinal stromal tumours with pathology correlation. J Comput Assist Tomogr. 2004;28(6):811-17.

[12] Buckley JA, Fishman EK. CT evaluation of small bowel neoplasms: Spectrum of disease. Radiographics. 1998;18(2):379-92.

[13] Freeny PC, Marks WM, Ryan JA, Bolen JW. Colorectal carcinoma evaluation with CT: preoperative staging and detection of postoperative recurrence. Radiology. 1986;158(2):347-53.

[14] Balthazar EJ, Noordhoorn M, Megibow AJ, Gordon RB. CT of small-bowel lymphoma in immunocompetent patients and patients with AIDS: Comparison of findings. Am J Roentgenol. 1997;168(3):675-80.

[15] Hussain SM, Outwater EK, Siegelman ES. Mucinous versus nonmucinous rectal carcinomas: differentiation with MR imaging. Radiology. 1999;213(1):79-85.

\section{PARTICULARS OF CONTRIBUTORS:}

1. Assistant Professor, Department of Radiology, Maharajah's Institute of Medical Sciences (MIMS), Vizianagaram, Andhra Pradesh, India.

2. Associate Professor, Department of Radiodiagnosis, GITAM Institute of Medical Sciences and Research, GITAM Deemed to be University, Visakhapatnam, Andhra Pradesh, India.

3. Specialist, Department of Radiology, Burjeel Day Surgery Centre, Abu Dhabi, United Arab Emirates.

4. Third Year Resident, Department of Endocrinology, JIPMER, Puducherry, Tamil Nadu, India.

NAME, ADDRESS, E-MAIL ID OF THE CORRESPONDING AUTHOR:

Devara Anil Kashi Vishnuvardhan,

Assistant Professor, Department of Radiology, Maharajah's Institute of Medical Sciences

(MIMS), Nellimarla, Vizianagaram District, Andhra Pradesh, India.

E-mail: rajaniagis@gmail.com; anilkashi@yahoo.com
PLAGIARISM CHECKING METHODS: [Jain Het al.

- Plagiarism X-checker: Sep 25, 2020

- Manual Googling: Feb 04, 2021

- iThenticate Software: Mar 13, 2021 (13\%)
ETYMOLOGY: Author Origin

\section{AUTHOR DECLARATION:}

- Financial or Other Competing Interests: None

- Was Ethics Committee Approval obtained for this study? No

- Was informed consent obtained from the subjects involved in the study? Yes

- For any images presented appropriate consent has been obtained from the subjects.
Date of Submission: Sep 24, 2020

Date of Peer Review: Nov 27, 2020

Date of Acceptance: Feb 11, 2021

Date of Publishing: Jul 01, 2021 